\title{
Risks and Benefits of Thrombolytic, Antiplatelet, and Anticoagulant Therapies for ST Segment Elevation Myocardial Infarction: Systematic Review
}

\author{
Bruno Ramos Nascimento, ${ }^{1,2,3}$ Marcos Roberto de Sousa, ${ }^{1}$ \\ Fábio Nogueira Demarqui, ${ }^{4}$ and Antonio Luiz Pinho Ribeiro ${ }^{1,3}$ \\ ${ }^{1}$ Serviço de Cardiologia e Cirurgia Cardiovascular, Hospital das Clínicas da Universidade Federal de Minas Gerais, \\ Avenida Professor Alfredo Balena 110, Campus Saúde, 30130-100 Belo Horizonte, MG, Brazil \\ ${ }^{2}$ Serviço de Hemodinâmca do Hospital Universitário São José (INCOR Minas), Rua Aimorés 2896, Barro Preto, \\ 30140-073 Belo Horizonte, MG, Brazil \\ ${ }^{3}$ Departamento de Clínica Médica da Faculdade de Medicina da Universidade Federal de Minas Gerais, \\ Avenida Professor Alfredo Balena 190, Campus Saúde, 30130-100 Belo Horizonte, MG, Brazil \\ ${ }^{4}$ Departamento de Estatística, Instituto de Ciências Exatas, Universidade Federal de Minas Gerais, \\ Avenida Antônio Carlos 6.627, Campus Pampulha, 31270-901 Belo Horizonte, MG, Brazil
}

Correspondence should be addressed to Bruno Ramos Nascimento; ramosnas@gmail.com

Received 14 October 2013; Accepted 26 November 2013; Published 6 February 2014

Academic Editors: P. Marino and M. Takahashi

Copyright (C) 2014 Bruno Ramos Nascimento et al. This is an open access article distributed under the Creative Commons Attribution License, which permits unrestricted use, distribution, and reproduction in any medium, provided the original work is properly cited.

\begin{abstract}
Objectives. Assess the impact of associating thrombolytics, anticoagulants, antiplatelets, and primary angioplasty (PA) on death, reinfarction (AMI), and major bleeding (MB) in STEMI therapy. Methods. Medline search was performed to identify randomized trials comparing these classes in STEMI treatment, at least 500 patients, providing death, AMI, and MB rates. Similar arms were grouped. Correlation between number of drugs and PA and the outcomes was evaluated, as well as correlation between the year of the study and the outcomes. Results. Fifty-nine papers remained after exclusions. 404.556 patients were divided into 35 groups of arms. There was correlation between the number of drugs and rates of death $(r=-0.466, P=0.005)$ and $\mathrm{MB}(r=0.403$, $P=0.016$ ), confirmed by multivariate regression. This model also showed that PA is associated with lower mortality and increased MB. Year and period of publication correlated with the outcomes: death $(r=-0.380, P<0.001), \operatorname{MB}(r=0.212, P=0.014)$, and AMI $(r=-0.231, P=0.009)$. Conclusion. The increasing complexity of STEMI treatment has resulted in significant reduction in mortality along with increased rates of MB. Overall, however, the benefits of treatment outweigh the associated risks of MB.
\end{abstract}

\section{Introduction}

Approximately 1.7 million people are hospitalized annually in the United States of America due to acute coronary syndromes (ACS), with almost one-quarter of cases showing ST-elevation acute myocardial infarction (STEMI) [1]. Its physiopathology is closely related to thrombus formation (after a complex process that culminates in platelet adhesion, activation and formation of platelet cluster) and activation of the coagulation cascade, over unstable atherosclerotic plaques $[2,3]$. With the evolution of STEMI treatment, drugs acting on these mechanisms: antiplatelet, anticoagulant, and thrombolytic therapies have been extensively tested in numerous studies, in different doses and associations, often in conjunction with interventional techniques, with significant reduction of morbi-mortality. However, there was also a marked increase in major bleeding rates, that is, difficult to measure objectively due to the lack of a standardized methodology for this purpose [4]. Besides this, drug associations not adequately tested in large trials have been incorporated by international guidelines [5-7]. 
Given the broad spectrum of clinical outcomes (with different definitions) and the heterogeneous criteria for adverse events (specially bleeding) reported in the numerous published studies, it's very difficult to estimate the real clinical benefit of each drug class for STEMI treatment. Pooled analysis of a significant number of studies is necessary, taking into account all the heterogeneity among them, in order to quantitatively evaluate the overall risk and benefit of the progressive addition of of drugs over time. A systematic review with quantitative approach may be a useful tool for this purpose, with its ability to incorporate the methodological issues observed $[8,9]$.

\section{Objectives}

To evaluate, by systematic review with quantitative analysis, the impact of the progressive addition of drug classes (thrombolytics, anticoagulants, and antiplatelets) and primary angioplasty (PA) on death, reinfarction (AMI), and major bleeding $(\mathrm{MB})$ rates in patients with STEMI.

\section{Materials and Methods}

Initially, a search was performed in Medline and Cochrane databases looking for articles with similar objectives and methodology. No similar publications were found.

A systematic medline search was performed using the MeSH terms: Acute [All Fields] AND myocardial infarction/therapy [Mesh Terms] AND (("1"[EDAT]: 2009/12/31 [EDAT]) AND humans [MeSH Terms] AND (English[lang] OR Spanish[lang] OR Portuguese[lang]) AND Randomized Controlled Trial[ptyp] AND adult[MeSH Terms]), to identify randomized trials in English and Spanish that compared drugs and interventional techniques for the acute treatment of STEMI.

Paper selection criteria were (1) randomized trials involving human adults and (2) comparing drugs in the treatment of STEMI: thrombolytics, antiplatelets, and anticoagulants. Studies comparing thrombolytics and PA were included. (3) Sample size: minimum 500 patients (defined to reduce inaccuracies in adverse events estimates and bias derived from published trials with reduced quality and power [10]) and (4) death, AMI and MB rates in the time frame closest to 30 days adequately provided.

The following aspects were observed: (a) defined inclusion criteria, sample selection explained, adequate description of diagnostic criteria, clinical and demographic characteristics and inclusion of all eligible patients; (b) objectives and results presented without explicit bias; (c) clinical variables clearly defined, including technical details of the treatments employed, clear definition of adverse cardiovascular events, and the bleeding criteria; (d) adequate statistical analysis with adjustment for all important factors.

Exclusion criteria were (1) nonrandomized studies; (2) studies with different scopes; (3) studies comparing interventions other than those mentioned, (4) studies involving only non-ST elevation acute coronary syndromes.
Article selection was independently done by two researchers (BRN and MRS), in three stages: (a) exclusion by title, (b) exclusion by abstract, and (c) exclusion by full text reading. Discrepancies were solved in consensus. Inclusion of additional data, provided by authors or contributors, was allowed as well as evaluation of related articles, editorials, and subanalyses.

After the final selection, demographic methodological, and clinical data were tabulated. Clinical outcomes and bleeding criteria were tabulated according to the trial's definitions. In some articles, when bleeding criteria were not explicit, we considered criteria previously reported in relevant publications.

Study arms were grouped by similarity, according to the association of therapeutic classes: aspirin (ASA), thienopyridines (TP), unfractionated heparin (UFH), low molecular weight heparin (LMWH), glycoprotein IIbIIIa (GPI), direct thrombin inhibitors (DTI), non fibrin-specific thrombolytics (streptokinase and urokinase-KS), fibrin-specific thrombolytics (FS), and PA. The class was considered when, in the arm, at least $50 \%$ of patients had received it. A regrouping was also carried out ("pure" groups), and the classes were considered when at least $85 \%$ of patients received them, with maximum contamination of $30 \%$ of drugs that were not part of the group's therapeutic regimen.

\section{Statistical Analysis}

We performed indirect comparisons between similar study arms [11]. Using the software Statistical Package for Social Sciences (SPSS) version 16.0.1 (IBM, Copyright 2007) a correlation (Spearman's test) between the number of drug classes and the clinical outcomes (death, AMI, and MB) was performed. We also tested the correlation between the year of the study's publication and the outcomes of interest. For this analysis, we considered the year of publication, and we also grouped the trials into five time periods: (a) up to 1989; (b) 1990-1994; (c) 1995-1999; (d) 2000-2004; (e) 20052009. The outcomes of the groups of study arms submitted to PA were compared with those not submitted by means of nonparametric tests. All the analysis was also performed for the "pure" groups. Additionally, a binomial multivariate regression model was adjusted, considering the number of classes used and PA as independent variables and death, AMI, and MB as outcomes, with the SAS/STAT Software, version 9.2 (Copyright SAS Institute Inc., Gary, NC, USA). A latent variable was inserted in this model to outweight the heterogeneity between trials, and the arms were weighted by sample size. A $P$ value of $<0.05$ was considered to be statistically significant.

\section{Results}

The search initially returned 2,313 articles. After the initial exclusion, 607 abstracts were selected, and 148 articles remained for full text reading, after which 59 articles were 


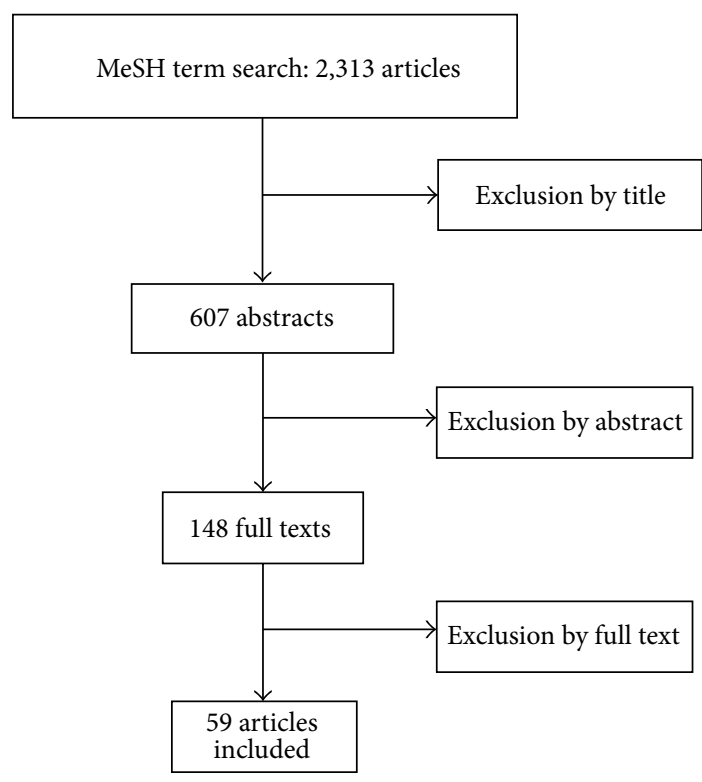

Figure 1: Flowchart of article selection by peer review.

included in the final database (Figure 1), totaling 133 treatment arms. The publication period was from 1985 to 2009 .

The total sample size was 404,556 patients, with average age of 61.0 years: $39.9 \%$ were hypertensive, $15.0 \%$ diabetic, $47.3 \%$ were smokers, and $14.2 \%$ had a history of prior AMI. Regarding treatment, $89.8 \%$ received ASA, $20.4 \%$ underwent $\mathrm{PA}, 25.0 \%$ received TP, $73.4 \%$ received UFH, $8.0 \%$ received LMWH, $16.1 \%$ received GPI, $4.5 \%$ received DTI, and $71.2 \%$ received thrombolytics (47.0\% FS and $27.2 \%$ FS). The weighted average follow-up time was 23.3 days. The arms were grouped by similarity in 35 groups, according to the described definition (Table 1 [12-71]).

Nineteen different major bleeding criteria were identified. The most used was Thrombolysis In Myocardial Infarction (TIMI [72]) criteria, followed by the need for any transfusion, the Global Use of Strategies to Open Occluded Coronary Arteries (GUSTO [60]) and the modified GUSTO criteria (excluding hemorrhagic stroke), present in $21.1 \%, 18.8 \%$, $18.0 \%$, and $8.1 \%$ of the study arms, respectively. There was a wide variability in the clinical and laboratorial definitions for the different bleeding criteria found, and their severity diverged considerably (Table $2[60,72]$ ).

5.1. Correlation: Number of Drugs and Primary Angioplasty and Adverse Events. Considering the 35 therapy groups, there was a statistically significant correlation between the number of drugs used and the rates of death $(r=-0.466, P=$ $0.005)$ and $\mathrm{MB}(r=0.403, P=0.016)$ (Figure 2) without correlation with AMI $(r=-0.034, P=0.847)$. Graphically, the mortality line is steeper compared to the bleeding line in these correlations.

Similarly, comparing the proportions of these outcomes between the groups in which PA was performed with the groups not submitted to intervention, the first had significantly lower mortality $(3.98 \pm 1.81 \times 7.56 \pm 2.45, P=0.001)$ and a higher rate of $\mathrm{MB}(5.71 \pm 5.22 \times 1.64 \pm 1.46, P=0.006)$, with similar AMI rates $(P=0.286)$. The findings were similar for the "pure" arms.

5.2. Multivariate Regression Model. The adjusted multivariate regression model showed negative association between the number of drugs used and mortality $(\beta=-0.233, P<0.001)$ and positive association between this number and the rates of $\mathrm{MB}(\beta=0.405, P=0.012)$. In addition, $\mathrm{PA}$ also had negative association with death $(\beta=-1.605, P<0.001)$ and positive association with $\mathrm{MB}(\beta=2.251, P=0.039)$. This data confirms the correlation's findings. However, in the presence of PA, the odds ratio for mortality reduction by the addition of one drug class loses significance, suggesting additional benefit of intervention. Similarly in the MB model, although there is association between the number of drugs and PA with this outcome, in patients undergoing PA the effect of the addition of a drug class on MB rates loses significance. In all models, the effect of the latent variable was significant, meaning significant heterogeneity between trials (Table 3 ).

The outcome AMI did not have significant association with the number of drugs $(\beta=0.036, P=0.550)$ and the performance of PA ( $\beta=0.629, P=0.197)$ similarly to the correlation models.

5.3. Correlation: Year and Period of Publication and Adverse Events. The year of publication had a statistically significant correlation with the three outcomes assessed: death $(r=$ $-0.380, P<0.001)$, AMI $(r=-0.231, P=0.009)$, and MB $(r=0.212, P=0.014)$ (Figure 3). Similarly, the five periods in which the publication years were grouped (weight $=1$ for every five years) had a statistically significant correlation with the rates of these three outcomes (resp., $r=-0.325$, $P<0.001, r=-0.236, P=0.007, r=0.214, P=$ 0.013). Considering only the 21 groups of "pure" arms, the correlation remained statistically significant for death $(r=$ $-0.272, P=0.010)$ and AMI $(r=-0.366, P=0.001)$ but not for MB.

\section{Discussion}

Since the first studies involving the treatment of STEMI, there has been debate about the "risk versus benefit" of prescribing drugs that are potentially related to coagulation. In the first large-scale studies $[49,73,74]$, the measurement of this net benefit was simpler, since the reduced number of classes involved made individual effects on major adverse events easier to evaluate. Besides this, considering that STEMI was a disease practically without specific treatment, the clinical benefit of introducing the first antiplatelets and reperfusion strategies [49, 73-78] was clearly relevant.

As treatment regimens became more complex, drug interaction started to play a role in this scenario and so did the large variability of doses tested (and their adjustment to specific populations), making it progressively more difficult to compare drug classes. We opted to perform indirect comparisons as a way to estimate numerically the effect of adding therapies, by grouping heterogeneous arms of studies, 
TABLE 1: Groups of treatment regimens (grouping of similar arms) and pure groups.

\begin{tabular}{|c|c|c|c|c|c|c|}
\hline Number & Regimen & Studies (references) & Number of arms & $\mathrm{N}$ & $\begin{array}{l}\text { Number of } \\
\text { "pure" arms }\end{array}$ & $\begin{array}{c}\mathrm{N} \text { in "pure" } \\
\text { arms }\end{array}$ \\
\hline 1 & $\mathrm{ASA}+\mathrm{PA}+\mathrm{TP}+\mathrm{UFH}+\mathrm{GPI}$ & [12-19] & 13 & 9,369 & 10 & 4,997 \\
\hline 2 & $\mathrm{ASA}+\mathrm{PA}+\mathrm{TP}+\mathrm{DTI}$ & {$[20]$} & 1 & 1,800 & 1 & 1,800 \\
\hline 3 & $\mathrm{ASA}+\mathrm{PA}+\mathrm{TP}+\mathrm{UFH}+\mathrm{GPI}+\mathrm{FS}$ & {$[21]$} & 1 & 298 & 1 & 298 \\
\hline 4 & $\mathrm{ASA}+\mathrm{TP}+\mathrm{UFH}+\mathrm{GPI}+\mathrm{FS}$ & {$[21]$} & 1 & 300 & 1 & 300 \\
\hline 5 & $\mathrm{ASA}+\mathrm{UFH}+\mathrm{FS}$ & {$[22-43]$} & 38 & 104,754 & 33 & 82,283 \\
\hline 6 & $\mathrm{ASA}+\mathrm{UFH}+\mathrm{GPI}+\mathrm{FS}$ & {$[22]$} & 1 & 8,328 & 1 & 8,328 \\
\hline 7 & $\mathrm{ASA}+\mathrm{PA}+\mathrm{GPI}$ & {$[44]$} & 1 & 2,885 & - & - \\
\hline 8 & $\mathrm{ASA}+\mathrm{PA}+\mathrm{TP}+\mathrm{GPI}$ & {$[44]$} & 1 & 2,860 & - & - \\
\hline 9 & $\mathrm{ASA}+\mathrm{LMWH}+\mathrm{FS}$ & {$[23,45]$} & 2 & 12,296 & 1 & 2,040 \\
\hline 10 & $\mathrm{ASA}+\mathrm{PA}+\mathrm{TP}+\mathrm{UFH}$ & {$[12,14,15,46,47]$} & 5 & 2,647 & 3 & 1,922 \\
\hline 11 & $\mathrm{ASA}+\mathrm{TP}+\mathrm{LMWH}+\mathrm{FS}$ & {$[45]$} & 1 & 818 & - & - \\
\hline 12 & $\mathrm{ASA}+\mathrm{TP}+\mathrm{UFH}+\mathrm{FS}$ & {$[39,45,46]$} & 3 & 2,992 & - & - \\
\hline 13 & $\mathrm{ASA}+\mathrm{LMWH}+\mathrm{KS}$ & {$[48]$} & 1 & 253 & 1 & 253 \\
\hline 14 & $\mathrm{ASA}+\mathrm{KS}$ & {$[30,48-53]$} & 7 & 29,824 & 4 & 3,428 \\
\hline 15 & $\mathrm{ASA}+\mathrm{DTI}+\mathrm{KS}$ & {$[54,55]$} & 2 & 9,119 & 2 & 9,119 \\
\hline 16 & $\mathrm{ASA}+\mathrm{UFH}+\mathrm{KS}$ & $\begin{array}{c}{[30,32,36,37,40} \\
55-60]\end{array}$ & 15 & 75,382 & 13 & 46,292 \\
\hline 17 & $\mathrm{ASA}+\mathrm{PA}+\mathrm{UFH}$ & {$[27,61]$} & 3 & 826 & 2 & 584 \\
\hline 18 & $\mathrm{ASA}+\mathrm{FS}$ & {$[30,41,52,53,62]$} & 7 & 38,298 & 2 & 1,471 \\
\hline 19 & $\mathrm{ASA}+\mathrm{UFH}+\mathrm{FS}+\mathrm{KS}$ & {$[40,60]$} & 2 & 10,471 & 2 & 10,471 \\
\hline 20 & $\mathrm{ASA}+\mathrm{PA}+\mathrm{UFH}+\mathrm{GPI}$ & {$[61]$} & 1 & 241 & 1 & 241 \\
\hline 21 & $\mathrm{ASA}+\mathrm{DTI}+\mathrm{FS}$ & {$[34]$} & 1 & 1,511 & - & - \\
\hline 22 & $\mathrm{TP}+\mathrm{KS}$ & {$[51]$} & 1 & 450 & 1 & 450 \\
\hline 23 & $\mathrm{UFH}+\mathrm{FS}$ & {$[63,64]$} & 2 & 3,136 & 2 & 3,136 \\
\hline 24 & UFH & [63-65] & 3 & 4,200 & 3 & 4,200 \\
\hline 25 & $\mathrm{ASA}+\mathrm{UFH}$ & {$[38,42,58,59]$} & 4 & 4,387 & 3 & 1,512 \\
\hline 26 & ASA & {$[49,50]$} & 2 & 10,854 & 1 & 2,259 \\
\hline 27 & $\mathrm{ASA}+\mathrm{PA}+\mathrm{UFH}+\mathrm{FS}$ & {$[66]$} & 1 & 195 & - & - \\
\hline 28 & $\mathrm{ASA}+\mathrm{TP}+\mathrm{LMWH}+\mathrm{GPI}+\mathrm{FS}$ & {$[67]$} & 1 & 522 & - & - \\
\hline 29 & $\mathrm{ASA}+\mathrm{PA}+\mathrm{TP}+\mathrm{LMWH}+\mathrm{GPI}+\mathrm{FS}$ & {$[67]$} & 1 & 537 & - & - \\
\hline 30 & $\mathrm{ASA}+\mathrm{TP}+\mathrm{UFH}+\mathrm{KS}$ & {$[56]$} & 1 & 22,961 & - & - \\
\hline 31 & $\mathrm{ASA}+\mathrm{TP}+\mathrm{KS}$ & {$[68,69]$} & 2 & 13,846 & - & - \\
\hline 32 & $\mathrm{ASA}+\mathrm{TP}+\mathrm{LMWH}+\mathrm{KS}$ & {$[68,69]$} & 2 & 13,816 & - & - \\
\hline 33 & $\mathrm{ASA}+\mathrm{PA}+\mathrm{TP}+\mathrm{UFH}+\mathrm{FS}$ & [17] & 1 & 829 & - & - \\
\hline 34 & KS & {$[70,71]$} & 2 & 6,211 & - & - \\
\hline 35 & $\mathrm{UFH}+\mathrm{KS}$ & {$[65,70]$} & 2 & 1,488 & - & - \\
\hline
\end{tabular}

ASA: acetylsalicyclic acid, PA: primary angioplasty, TP: thienopyridines, UFH: unfractionated heparin, LMWH: low molecular weight heparin, GPI: glycoprotein IIbIIIa inhibitors, DTI: direct thrombin inhibitors, FS: fibrin specific thrombolytics and KS: kinase type thrombolytics (streptokinase and urokinase).

covering all STEMI pharmacological treatment periods $[9$, $79,80]$. Methodologically, a reliable estimate of the effect may be obtained when direct comparisons are not feasible, even considering the loss of randomization [11, 81].

The correlation between number of drugs used and the reduction of mortality and the correlation between this outcome and the year/period of publication of the study are in accordance with previously published data [82]. Graphically, there seems to be a trend towards greater reduction of mortality rates compared to $\mathrm{MB}$ (Figures 2 and 3 ), indirectly suggesting that the clinical benefit may still be overlapping the increasing bleeding risk. This balance, however, is probably 
TABLE 2: Bleeding criteria found in studies and number of arms that consider each of them.

\begin{tabular}{|c|c|c|}
\hline Number & Criteria & Number (\%) of arms \\
\hline 1 & TIMI [72] criteria & $28(21.1 \%)$ \\
\hline 2 & GUSTO $[60]$ criteria & $24(18.0 \%)$ \\
\hline 3 & Intraocular, retroperitoneal bleeding, transfusion or drop of $50 \mathrm{~g} / \mathrm{L} \mathrm{Hb}$ & $2(1.5 \%)$ \\
\hline 4 & Fatal bleeding or bleeding requiring transfusion & $2(1.5 \%)$ \\
\hline 5 & GUSTO [60] criteria, excluding hemorrhagic stroke & $11(8.3 \%)$ \\
\hline 6 & $\begin{array}{l}\text { Fatal bleeding, transfusion of } 2 \mathrm{U} \text {, drop of } 3 \mathrm{~g} / \mathrm{dL} \mathrm{Hb} \text {, retroperitoneal, intracranial, ocular or } \\
\text { requiring intervention }\end{array}$ & $2(1.5 \%)$ \\
\hline 7 & Need for any transfusion & $25(18.8 \%)$ \\
\hline 8 & Hemorrhagic stroke or transfusion of $2 \mathrm{U}$ & $2(1.5 \%)$ \\
\hline 9 & $\begin{array}{l}\text { Fatal or life threatening bleeding, requiring intervention, prolonged hospitalization, with } \\
\text { significant systemic dysfunction }\end{array}$ & $4(3.0 \%)$ \\
\hline 10 & Transfusion of at least $2 \mathrm{U}$, fatal or intracranial bleeding & $2(1.5 \%)$ \\
\hline 11 & Fall in $\mathrm{Hb}$ of at least $2 \mathrm{mmol} / \mathrm{L}$, transfusion of $2 \mathrm{U}$, need for intervention or intracranial bleeding & $2(1.5 \%)$ \\
\hline 12 & $\begin{array}{l}\text { Transfusion or bleeding excluding puncture site, subcutaneous, hematuria or any drop in } \mathrm{Hb} \\
\text { described as not serious }\end{array}$ & $2(1.5 \%)$ \\
\hline 13 & $\begin{array}{l}\text { Severe bleeding of the gastrointestinal tract, resulting in shock or transfusion, critical bleeding } \\
\text { and hemorrhagic stroke }\end{array}$ & $2(1.5 \%)$ \\
\hline 14 & $\begin{array}{l}\text { Nonminor transfusion and bleeding (except puncture site bleeding, streaks of blood in feces and } \\
\text { vomit, epistaxis, etc.) }\end{array}$ & $3(2.3 \%)$ \\
\hline 15 & Transfusion of at least $2 \mathrm{U}$ & $8(6.0 \%)$ \\
\hline 16 & Hematemesis, melena, hematuria, and severe hemoptysis & $2(1.5 \%)$ \\
\hline 17 & $\begin{array}{l}\text { Hemorrhagic stroke, hematemesis, severe hematuria, prolonged bleeding, and large hematoma at } \\
\text { puncture site }\end{array}$ & $2(1.5 \%)$ \\
\hline 18 & Criteria: gastrointestinal and retroperitoneal bleeding, hemorrhagic stroke & $4(3.0 \%)$ \\
\hline 19 & Hemorrhagic stroke & $6(4.5 \%)$ \\
\hline
\end{tabular}

Hb: hemoglobin; U: international unit of red blood cells-300 mL; CVA: cerebrovascular accident/stroke.

TABLE 3: Multivariate regression with binomial response for death, acute myocardial infarction and major bleeding, with number of drugs ( $\mathrm{N}$ drugs) and primary angioplasty $(\mathrm{PA})$ as independent variables.

\begin{tabular}{lccccccccc}
\hline Outcome & \multicolumn{3}{c}{ Death } & \multicolumn{3}{c}{ Major bleeding } & \multicolumn{3}{c}{ AMI } \\
Parameter & $\beta$-Coefficient & Standard error & $P$ & $\beta$-Coefficient & Standard error & $P$ & $\beta$-Coefficient & Standard error & $P$ \\
\hline N drugs & -0.233 & 0.054 & $<0.001^{*}$ & 0.405 & 0.154 & $0.012^{*}$ & -0.039 & 0.064 & 0.550 \\
PA & -1.605 & 0.409 & $<0.001^{*}$ & 2.251 & 1.049 & $0.039^{*}$ & -0.629 & 0.478 & 0.197 \\
Interaction1 & $0.294^{\mathrm{a}}$ & 0.120 & $0.019^{*}$ & $-0.355^{\mathrm{a}}$ & 0.308 & 0.258 & $-0.162^{\mathrm{a}}$ & 0.142 & 0.262 \\
Latent variable & 0.079 & 0.022 & $0.001^{*}$ & 0.670 & 0.176 & $<0.001^{*}$ & 0.111 & 0.033 & $0.002^{*}$ \\
\hline & Odds & \multicolumn{2}{c}{ IC 95\% } & Odds & IC 95\% & Odds & IC 95\% \\
\hline PA - & 0,791 & $0,704-0,879$ & 1,499 & $1,030-1,968$ & & 0,961 & $0,836-1,088$ \\
PA + & 1,062 & $0,831-1,293$ & & 1,051 & $0,480-1,622$ & & 1,131 & $0,840-1,422$ \\
\hline
\end{tabular}

Latent variable inserted in the model to minimize the variability effect between studies. Interactions tested in models: ${ }^{a}$ drugs: PA; ${ }^{b} \mathrm{PA}$ : bleeding and ${ }^{\mathrm{c}} \mathrm{PA}:$ death, (without statistical significance). IC 95\%: reliability interval 95\%.

${ }^{*} P<0.05$.

close to its limit. The significantly lower mortality in the groups submitted to PA confirms its well-known additional benefit that might hide a possible near-equivalence between mortality reduction and increased bleeding associated with thrombolysis. This hypothesis is reinforced by a significant loss of interaction between the number of drugs and mortality in the presence of PA.

Although there are specific recommendations for the definition of bleeding events [83], we observed a large number of criteria, some of which developed for specific trials (Table 2), often with prognostic accuracy not well established [84]. Despite this heterogeneity, a considerable number of studies used two of the most accepted criteria-TIMI and GUSTO $[60,72]$ : the first is essentially based on laboratory data, while the second relies on clinical observations and seems to have a greater prognostic value [85]. However, it does not appear to be a trend towards standardization in the most recent large-scale trials $[20,86,87]$. This lack of 


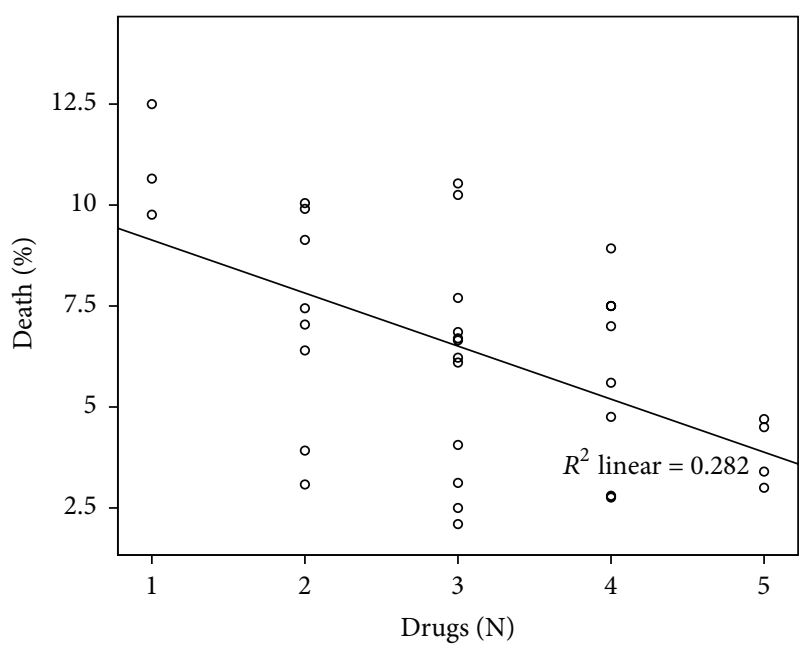

(a)

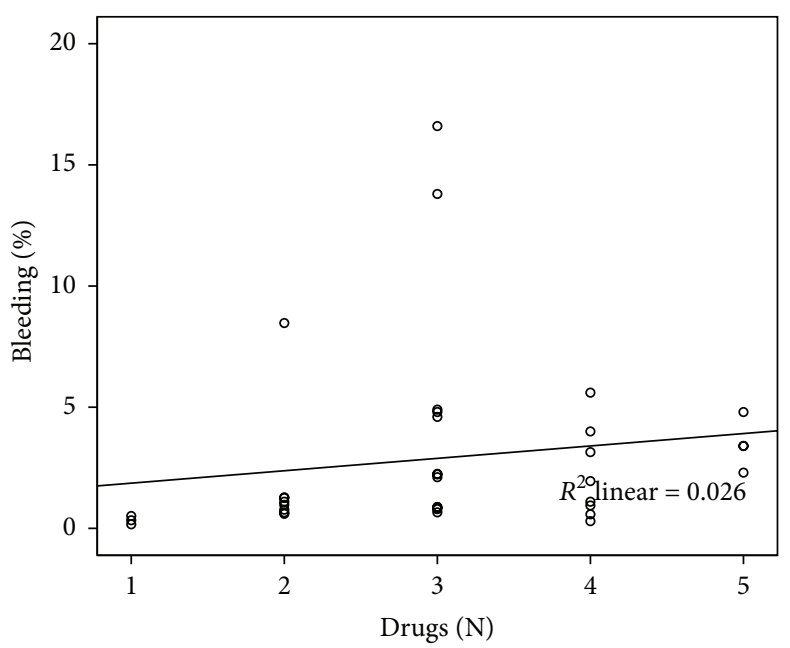

(b)

FIGURE 2: Correlation between number of classes of drugs and (a) mortality $(r=-0.466, P=0.005)$ and between number of classes of drugs and (b) major bleeding $(r=0.403, P=0.016)$.

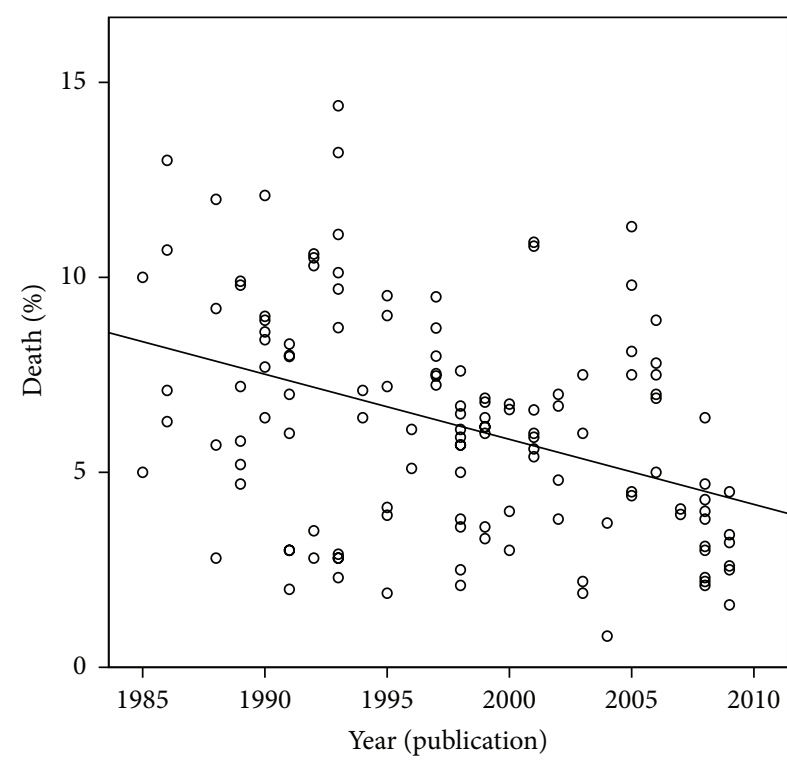

(a)

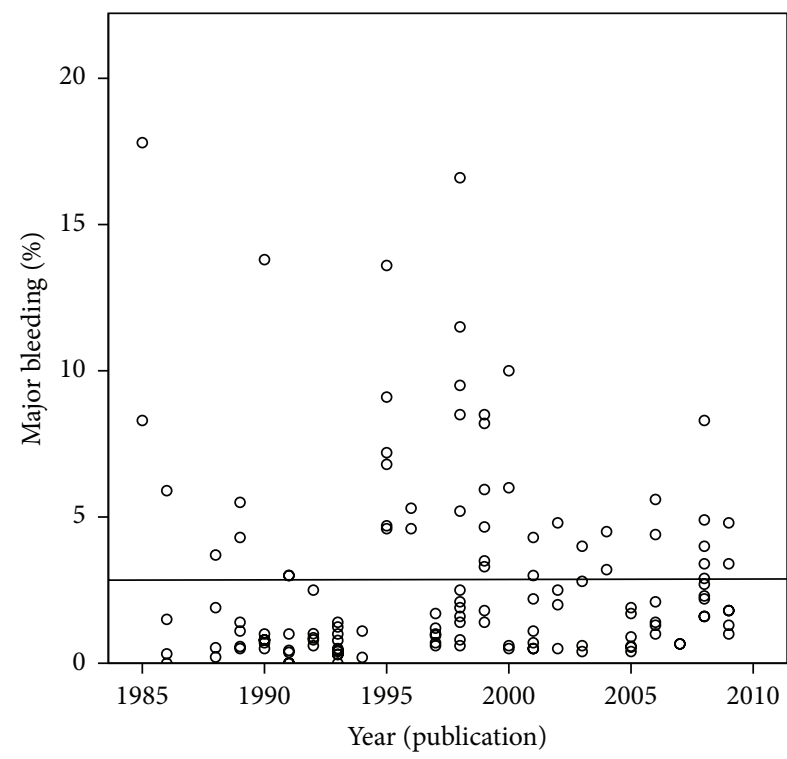

(b)

FIGURE 3: Correlation between year of publication and (a) mortality $(r=-0.380, P<0.001)$ and between year of publication and (b) major bleeding $(r=0.212, P=0.014)$.

standardization, besides making it more difficult to compare the safety of therapeutic strategies, raises critical questions about the possible adjustment of specific criteria, aiming to favor the results of a drug class under evaluation.

There's a temporal trend towards increased rates of $\mathrm{MB}$, related to the increasing complexity of therapies (number of drugs), currently averaging around 3-4\% (Figures 2 and $3)$. Given the known relationship of bleeding complications with prognosis $[84,88]$, we must be aware of this fact, since some associations recommended by guidelines [5-7] were systematically tested only in separate $[23,39,45,56]$.
Considering that part of the cumulative benefit over mortality may be related to the advent of PA (as pointed out by the the regression model), in the arms that used thombolyticsagents with potential bleeding effect-there, may be a trend to nullify the net benefit. On the other hand, this hypothesis is counterbalanced by the observed association between PA and increased MB: in its presence, the effect of adding one class of drug on bleeding complications becomes not significant. One must also consider that PA became a routine procedure when more aggressive antiplatelet and anticoagulant strategies were already established. 
Previously published data showed significant bias related to the risk profile of randomized and nonrandomized patients in large studies, besides the fact that the inclusion of unpublished studies may improve the accuracy of risk estimates $[89,90]$. The compilation of a large volume of data, including studies with a considerable sample size ( $>500$ patients), may dilute these biases, but they should be considered when analyzing the external validity of the review.

Despite these considerations, the trend towards mortality reduction and increased $\mathrm{MB}$ as drugs were added over time are plausible and consistently demonstrated by two different analytic models. This review highlights the need for standardization of the methodology for assessing $\mathrm{MB}$ complications in randomized trials, as recommended by the literature, in order to make possible accurate inferences about the risk/benefit profile of drug associations.

\section{Limitations}

The main limitations of this analysis are related to the methodology of systematic reviews and metaanalysis with indirect comparisons itself. Qualitatively, one should note the different eras of clinical research covered by the publications (1985 to 2009), which itself accounts for the great methodological discrepancies, related to sample selection and allocation, study design, definitions of outcomes and clinical endpoints and follow-up strategies. Besides that, the results may also be influenced by the wide variability of $\mathrm{MB}$ definitions and the great heterogeneity of drug associations, doses, and regimens. Similarly, the techniques and results of PA have significantly improved over the decades covered by this review. Such differences make secondary data analysis even more susceptible to bias and the direct comparison between groups methodologically impossible.

For this reason, indirect comparisons were performed between groups. This methodology can be applied when arms of studies with different therapeutic schemes are found. At the cost of loss of the randomization effect, with this approach it is possible to obtain an estimate without treatment effect bias, even if treatment and control arms differ in their baseline characteristics, as observed in this heterogeneous sample of trials [11, 81]. However, in the adjusted models, a weight $=1$ was attributed to all drug classes, which must be carefully interpreted, since the benefit/harm profile of the drugs may vary and cannot be precisely estimated. Thus, no extrapolations can be made about the effect of each specific class nor about the odds for adverse events in a specific therapeutic scheme.

\section{Conclusion}

This systematic review with quantitative analysis demonstrated a negative association between the number of classes of drugs used for the acute treatment of STEMI and mortality rates and a positive association with MB. From the perspective of the main trials involving STEMI treatment, the optimal therapy recommended by guidelines is in the boundary of clinical benefit, with mortality rates currently around 5\%, at the expense of increasing bleeding complications, apparently of lesser magnitude up to this point. Our findings depict numerically subjective observations: it seems that the net clinical benefit still outweighs the bleeding risk. Additional studies and metaanalysis with individual associations are necessary to clearly estimate the benefit of specific therapies, especially in complex associations.

\section{Conflict of Interests}

The authors declare that there is no conflict of interests regarding the publication of this paper.

\section{References}

[1] American Heart Association, Heart and Stroke Statistical Update, 2007, http://www.americanheart.org.

[2] B. Phibbs, F. Marcus, H. J. Marriott, A. Moss, and D. H. Spodick, "Q-wave versus non-Q wave myocardial infarction: a meaningless distinction," Journal of the American College of Cardiology, vol. 33, no. 2, pp. 576-582, 1999.

[3] D. P. Zippes, P. Libby, R. O. Bonow, and E. Braunwald, Hemostasis, Thrombosis, Fibrinolisys and Cardiovascular Disease, Braunwald: Heart Disease, Elsevier, Amsterdam, The Netherlands, 2005.

[4] I. Pitrou, I. Boutron, N. Ahmad, and P. Ravaud, "Reporting of safety results in published reports of randomized controlled trials," Archives of Internal Medicine, vol. 169, no. 19, pp. 17561761, 2009.

[5] E. M. Antman, D. T. Anbe, P. W. Armstrong et al., "ACC/AHA guidelines for the management of patients with ST-elevation myocardial infarction: a report of the American College of Cardiology/American Heart Association Task Force on Practice Guidelines (Committee to Revise the 1999 Guidelines for the Management of Patients with Acute Myocardial Infarction)," Circulation, vol. 110, pp. 588-636, 2004.

[6] E. M. Antman, M. Hand, P. W. Armstrong et al., "2007 Focused update of the ACC/AHA 2004 guidelines for the management of patients with ST-elevation myocardial infarction: a report of the American College of Cardiology/American Heart Association task force on practice guidelines: developed in collaboration With the Canadian Cardiovascular Society endorsed by the American Academy of Family Physicians: 2007 Writing Group to Review New Evidence and Update the ACC/AHA, 2004 Guidelines for the Management of Patients With ST-Elevation Myocardial Infarction, Writing on Behalf of the 2004 Writing Committee," Circulation, vol. 117, no. 2, pp. 296-329, 2008.

[7] F. van de Werf, J. Bax, A. Betriu et al., "Management of acute myocardial infarction in patients presenting with persistent STsegment elevation: the Task Force on the Management of STSegment Elevation Acute Myocardial Infarction of the European Society of Cardiology," Giornale Italiano di Cardiologia, vol. 29, no. 23, pp. 2909-2945, 2008.

[8] D. Moher, A. Liberati, J. Tetzlaff, and D. G. Altman, "Reprintpreferred reporting items for systematic reviews and metaanalyses: the PRISMA statement," Physical Therapy, vol. 89, no. 9, pp. 873-880, 2009.

[9] A. Liberati, D. G. Altman, J. Tetzlaff et al., "The PRISMA statement for reporting systematic reviews and meta-analyses 
of studies that evaluate health care interventions: explanation and elaboration," Annals of Internal Medicine, vol. 151, no. 4, pp. W65-W94, 2009.

[10] C. O. Phillips, A. Kashani, D. K. Ko, G. Francis, and H. M. Krumholz, "Adverse effects of combination angiotensin II receptor blockers plus angiotensin-converting enzyme inhibitors for left ventricular dysfunction: a quantitative review of data from randomized clinical trials," Archives of Internal Medicine, vol. 167, no. 18, pp. 1930-1936, 2007.

[11] H. C. Bucher, G. H. Guyatt, L. E. Griffith, and S. D. Walter, “The results of direct and indirect treatment comparisons in metaanalysis of randomized controlled trials," Journal of Clinical Epidemiology, vol. 50, no. 6, pp. 683-691, 1997.

[12] A. W. van’t Hof, J. Ten Berg, T. Heestermans et al., "Prehospital initiation of tirofiban in patients with ST-elevation myocardial infarction undergoing primary angioplasty (On-TIME 2): a multicentre, double-blind, randomised controlled trial," The Lancet, vol. 372, no. 9638, pp. 537-546, 2008.

[13] G. Montalescot, S. D. Wiviott, E. Braunwald et al., "Prasugrel compared with clopidogrel in patients undergoing percutaneous coronary intervention for ST-elevation myocardial infarction (TRITON-TIMI 38): double-blind, randomised controlled trial," The Lancet, vol. 373, no. 9665, pp. 723-731, 2009.

[14] J. Mehilli, A. Kastrati, S. Schulz et al., "Abciximab in patients with acute sT-segment-elevation myocardial infarction undergoing primary percutaneous coronary intervention after clopidogrel loading a randomized double-blind trial," Circulation, vol. 119, no. 14, pp. 1933-1940, 2009.

[15] J. E. Tcheng, D. E. Kandzari, C. L. Grines et al., "Benefits and risks of abciximab use in primary angioplasty for acute myocardial infarction: the controlled abciximab and device investigation to lower late angioplasty complications (CADILLAC) trial," Circulation, vol. 108, no. 11, pp. 1316-1323, 2003.

[16] M. Valgimigli, G. Campo, G. Percoco et al., "Comparison of angioplasty with infusion of tirofiban or abciximab and with implantation of sirolimus-eluting or uncoated stents for acute myocardial infarction: the multistrategy randomized trial," Journal of the American Medical Association, vol. 299, no. 15, pp. 1788-1799, 2008.

[17] F. van de Werf, "Primary versus tenecteplase-facilitated percutaneous coronary intervention in patients with ST-segment elevation acute myocardial infarction (ASSENT-4 PCI): randomised trial," The Lancet, vol. 367, no. 9510, pp. 569-578, 2006.

[18] A. W. van't Hof, N. Ernst, M. J. de Boer et al., "FT Facilitation of primary coronary angioplasty by early start of a glycoprotein $2 b / 3 a$ inhibitor: results of the ongoing tirofiban in myocardial infarction evaluation (On-TIME) trial," European Heart Journal, vol. 25, no. 10, pp. 837-846, 2004.

[19] G. W. Stone, B. Witzenbichler, G. Guagliumi et al., "Bivalirudin during primary PCI in acute myocardial infarction," The New England Journal of Medicine, vol. 358, no. 21, pp. 2218-2230, 2008.

[20] R. Mehran, B. Brodie, D. A. Cox et al., "The harmonizing outcomes with RevascularIZatiON and stents in acute myocardial infarction (HORIZONS-AMI) trial: study design and rationale," The American Heart Journal, vol. 156, no. 1, pp. 44-56, 2008.

[21] C. di Mario, D. Dudek, F. Piscione et al., "Immediate angioplasty versus standard therapy with rescue angioplasty after thrombolysis in the combined abciximab REteplase stent study in acute myocardial infarction (CARESS-in-AMI): an open, prospective, randomised, multicentre trial," The Lancet, vol. 371, no. 9612, pp. 559-568, 2008.

[22] E. J. Topol, "Reperfusion therapy for acute myocardial infarction with fibrinolytic therapy or combination reduced fibrinolytic therapy and platelet glycoprotein IIb/IIIa inhibition: the GUSTO V randomised trial," The Lancet, vol. 357, no. 9272, pp. 1905-1914, 2001.

[23] E. M. Antman, D. A. Morrow, C. H. McCabe et al., "Enoxaparin versus unfractionated heparin with fibrinolysis for ST-elevation myocardial infarction," The New England Journal of Medicine, vol. 354, no. 14, pp. 1477-1488, 2006.

[24] F. J. van de Werf, "Efficacy and safety of tenecteplase in combination with enoxaparin, abciximab, or unfractionated heparin: the ASSENT-3 randomised trial in acute myocardial infarction," The Lancet, vol. 358, no. 9282, pp. 605-613, 2001.

[25] F. van de Werf, J. Adgey, D. Ardissino et al., "Single-bolus tenecteplase compared with front-loaded alteplase in acute myocardial infarction: the ASSENT-2 double-blind randomised trial," The Lancet, vol. 354, no. 9180, pp. 716-722, 1999.

[26] R. G. Wilcox, E. Antman, E. Braunwald, and A. Skene, "Intravenous NPA for the treatment of infarcting myocardium early. InTIME-II, a double-blind comparison on of single-bolus lanoteplase vs accelerated alteplase for the treatment of patients with acute myocardial infarction," European Heart Journal, vol. 21, no. 24, pp. 2005-2013, 2000.

[27] A. Liem, F. Zijlstra, J. P. Ottervanger et al., "High dose Heparin as pretreatment for primary angioplasty in acute myocardial infarction: the Heparin in Early Patency (HEAP) randomized trial," Journal of the American College of Cardiology, vol. 35, no. 3, pp. 600-604, 2000.

[28] F. van de Werf, C. P. Cannon, A. Luyten et al., "Safety assessment of single-bolus administration of TNK tissue- plasminogen activator in acute myocardial infarction: the ASSENT-1 trial," The American Heart Journal, vol. 137, no. 5, pp. 786-791, 1999.

[29] C. P. Cannon, C. M. Gibson, C. H. McCabe et al., “TNK-tissue plasminogen activator compared with front-loaded alteplase in acute myocardial infarction: results of the TIMI 10B trial," Circulation, vol. 98, no. 25, pp. 2805-2814, 1998.

[30] B. K. Metz, H. D. White, C. B. Granger et al., "Randomized comparison of direct thrombin inhibition versus heparin in conjunction with fibrinolytic therapy for acute myocardial infarction: results from the GUSTO-Ilb trial," Journal of the American College of Cardiology, vol. 31, no. 7, pp. 1493-1498, 1998.

[31] "A comparison of reteplase with alteplase for acute myocardial infarction. The Global Use of Strategies to Open Occluded Coronary Arteries (GUSTO III) Investigators," The New England Journal of Medicine, vol. 337, no. 16, pp. 1118-1123, 1997.

[32] U. Tebbe, R. Michels, J. Adgey et al., "Randomized, double-blind study comparing saruplase with streptokinase therapy in acute myocardial infarction: the COMPASS equivalence trial," Journal of the American College of Cardiology, vol. 31, no. 3, pp. 487-493, 1998.

[33] F. van de Werf, "A comparison of continuous infusion of alteplase with double-bolus administration for acute myocardial infarction," The New England Journal of Medicine, vol. 337, no. 16, pp. 1124-1130, 1997. 
[34] E. M. Antman, "Hirudin in acute myocardial infarction: thrombolysis and thrombin inhibition in myocardial infarction (TIMI) 9B trial," Circulation, vol. 94, no. 5, pp. 911-921, 1996.

[35] R. W. Smalling, C. Bode, J. Kalbfleisch et al., "More rapid, complete, and stable coronary thrombolysis with bolus administration of reteplase compared with alteplase infusion in acute myocardial infarction," Circulation, vol. 91, no. 11, pp. 27252732, 1995.

[36] R. G. Wilcox, "Randomised, double-blind comparison of reteplase double-bolus administration with streptokinase in acute myocardial infarction (INJECT): trial to investigate equivalence," The Lancet, vol. 346, no. 8971, pp. 329-336, 1995.

[37] G. A. Feruglio, A. Lotto, F. Rovelli et al., "GISSI-2: a factorial randomised trial of alteplase versus streptokinase and heparin versus no heparin among 12,490 patients with acute myocardial infarction," The Lancet, vol. 336, no. 8707, pp. 65-71, 1990.

[38] F. van de Werf and A. E. R. Arnold, "Intravenous tissue plasminogen activator and size of infarct, left ventricular function, and survival in acute myocardial infarction," British Medical Journal, vol. 297, no. 6660, pp. 1374-1379, 1988.

[39] M. S. Sabatine, C. P. Cannon, C. M. Gibson et al., "Addition of clopidogrel to aspirin and fibrinolytic therapy for myocardial infarction with ST-segment elevation," The New England Journal of Medicine, vol. 352, no. 12, pp. 1179-1189, 2005.

[40] R. M. Califf, E. J. Topol, R. S. Stack et al., "Evaluation of combination thrombolytic therapy and timing of cardiac catheterization in acute myocardial infarction: results of thrombolysis and angioplasty in myocardial infarction - Phase 5 randomized trial," Circulation, vol. 83, no. 5, pp. 1543-1556, 1991.

[41] D. P. de Bono, M. L. Simoons, J. Tijssen et al., "Effect of early intravenous heparin on coronary patency, infarct size, and bleeding complications after alteplase thrombolysis: results of a randomised double blind European Cooperative Study Group trial," British Heart Journal, vol. 67, no. 2, pp. 122-128, 1992.

[42] J. Hampton, R. Wilcox, P. Armstrong et al., "Late assessment of thrombolytic efficacy (LATE) study with alteplase 6-24 hours after onset of acute myocardial infarction," The Lancet, vol. 342, no. 8874 , pp. 759-766, 1993.

[43] E. Braunwald, G. L. Knatterud, M. L. Terrin et al., "Comparison of invasive and conservative strategies after treatment with intravenous tissue plasminogen activator in acute myocardial infarction. Results of the thrombolysis in myocardial infarction (TIMI) phase II trial," The New England Journal of Medicine, vol. 320, no. 10, pp. 618-627, 1989.

[44] P. W. Armstrong, P. X. Adams, H. R. Al-Khalidi et al., "Assessment of pexelizumab in acute myocardial infarction (APEX AMI): a multicenter, randomized, double-blind, parallel-group, placebo-controlled study of pexelizumab in patients with acute myocardial infarction undergoing primary percutaneous coronary intervention," The American Heart Journal, vol. 149, no. 3, pp. 402-407, 2005.

[45] F. J. van de Werf, "Efficacy and safety of tenecteplase in combination with enoxaparin, abciximab, or unfractionated heparin: the ASSENT-3 randomised trial in acute myocardial infarction," The Lancet, vol. 358, no. 9282, pp. 605-613, 2001.

[46] E. Bonnefoy, F. Lapostolle, A. Leizorovicz et al., "Primary angioplasty versus prehospital fibrinolysis in acute myocardial infarction: a randomised study," The Lancet, vol. 360, no. 9336, pp. 825-829, 2002.
[47] A. M. Ross, K. S. Coyne, J. S. Reiner et al., "A randomized trial comparing primary angioplasty with a strategy of shortacting thrombolysis and immediate planned rescue angioplasty in acute myocardial infarction: the PACT trial," Journal of the American College of Cardiology, vol. 34, no. 7, pp. 1954-1962, 1999.

[48] M. Simoons, M. Krzemiñska-Pakula, A. Alonso et al., "Improved reperfusion and clinical outcome with enoxaparin as an adjunct to streptokinase thrombolysis in acute myocardial infarction: the AMI-SK study," European Heart Journal, vol. 23, no. 16, pp. 1282-1290, 2002.

[49] "Randomised trial of intravenous streptokinase, oral aspirin, both, or neither among 17, 187 cases of suspected acute myocardial infarction: ISIS-2. ISIS-2 (Second International Study of Infarct Survival) Collaborative Group," The Lancet, vol. 2, no. 8607, pp. 349-360, 1988.

[50] "Randomised trial of late thrombolysis in patients with suspected acute myocardial infarction. EMERAS (Estudio Multicentrico Estreptoquinasa Republicas de America del Sur) Collaborative Group," The Lancet, vol. 342, no. 8874, pp. 767772, 1993.

[51] J. Santopinto, F. A. Cordero, D. Fainstein et al., "Randomized trial of ridogrel, a combined thromboxane A2 synthase inhibitor and thromboxane A2/prostaglandin endoperoxide receptor antagonist, versus aspirin as adjunct to thrombolysis in patients with acute myocardial infarction: the ridogrel versus aspirin patency trial (RAPT)," Circulation, vol. 89, no. 2, pp. 588-595, 1994.

[52] D. Hunt, J. Varigos, F. Dienstl et al., "ISIS-3: a randomised comparison of streptokinase vs tissue plasminogen activator vs anistreplase and of aspirin plus heparin vs aspirin alone among 41,299 cases of suspected acute myocardial infarction," The Lancet, vol. 339, no. 8796, pp. 753-770, 1992.

[53] F. van de Werf, R. G. Wilcox, G. I. Barbash et al., "In-hospital mortality and clinical course of 20,891 patients with suspected acute myocardial infarction randomised between alteplase and streptokinase with or without heparin," The Lancet, vol. 336, no. 8707, pp. 71-75, 1990.

[54] H. White, H. D. White, R. J. Simes et al., "Thrombin-specific anticoagulation with bivalirudin versus heparin in patients receiving fibrinolytic therapy for acute myocardial infarction: the HERO-2 randomised trial," The Lancet, vol. 358, no. 9296, pp. 1855-1863, 2001.

[55] K.-L. Neuhaus, G. P. Molhoek, U. Zeymer et al., "Recombinant hirudin (lepirudin) for the improvement of thrombolysis with streptokinase in patients with acute myocardial infarction: results of the HIT-4 trial," Journal of the American College of Cardiology, vol. 34, no. 4, pp. 966-973, 1999.

[56] Z. M. Chen, H. C. Pan, Y. P. Chen et al., "Early intravenous then oral metoprolol in 45, 852 patients with acute myocardial infarction: randomised placebo-controlled trial," The Lancet, vol. 366, no. 9497, pp. 1622-1632, 2005.

[57] H. White, H. D. White, R. J. Simes et al., “Thrombin-specific anticoagulation with bivalirudin versus heparin in patients receiving fibrinolytic therapy for acute myocardial infarction: the HERO-2 randomised trial," The Lancet, vol. 358, no. 9296, pp. 1855-1863, 2001.

[58] M. L. Simoons, P. W. Serruys, and M. v/d Brand, "Improved survival after early thrombolysis in acute myocardial infarction," The Lancet, vol. 2, no. 8455, pp. 578-582, 1985. 
[59] R. Schroder, K.-L. Neuhaus, and A. Leizorovicz, "A prospective trial of intravenous streptokinase in acute myocardial infarction (I.S.A.M.). Mortality, morbidity, and infarct size at 21 days," The New England Journal of Medicine, vol. 314, no. 23, pp. 1465-1471, 1986.

[60] The GUSTO investigators, "An international randomized trial comparing four thrombolytic strategies for acute myocardial infarction," The New England Journal of Medicine, vol. 329, no. 10, pp. 673-682, 1993.

[61] S. J. Brener, L. A. Barr, J. E. B. Burchenal et al., "Randomized, placebo-controlled trial of platelet glycoprotein IIb/IIIa blockade with primary angioplasty for acute myocardial infarction," Circulation, vol. 98, no. 8, pp. 734-741, 1998.

[62] P. Kuhn, K. Atzenhofer-Baumgartner, F. Chmelizek et al., "Prehospital thrombolytic therapy in patients with suspected acute myocardial infarction," The New England Journal of Medicine, vol. 329, no. 6, pp. 383-389, 1993.

[63] D. A. Chamberlain, D. P. De Bono, K. A. A. Fox et al., "Longterm effects of intravenous anisterplase in acute myocardial infarction: final report of the AIMS study," The Lancet, vol. 335, no. 8687, pp. 427-431, 1990.

[64] R. G. Wilcox, "Thrombolysis with tissue plasminogen activator in suspected acute myocardial infarction. The ASSET study," Chest, vol. 95, no. 5, 1989.

[65] P. Rossi and L. Bolognese, "Comparison of intravenous urokinase plus heparin versus heparin alone in acute myocardial infarction," The American Journal of Cardiology, vol. 68, no. 6, pp. 585-592, 1991.

[66] W. J. Rogers, D. S. Baim, J. M. Gore et al., "Comparison of immediate invasive, delayed invasive, and conservative strategies after tissue-type plasminogen activator. Results of the Thrombolysis in Myocardial Infarction (TIMI) Phase II-A Trial," Circulation, vol. 81, no. 5, pp. 1457-1476, 1990.

[67] W. J. Cantor, D. Fitchett, B. Borgundvaag et al., "Routine early angioplasty after fibrinolysis for acute myocardial infarction," The New England Journal of Medicine, vol. 360, no. 26, pp. 27052718, 2009.

[68] S. Yusuf, S. R. Mehta, S. Chrolavicius et al., "Effects of fondaparinux on mortality and reinfarction in patients with acute ST-segment elevation myocardial infarction: the OASIS-6 randomized trial," Journal of the American Medical Association, vol. 295, no. 13, pp. 1519-1530, 2006.

[69] S. Yusuf, S. R. Mehta, C. Xie et al., "Effects of reviparin, a low-molecular-weight heparin, on mortality, reinfarction, and strokes in patients with acute myocardial infarction presenting with ST-segment elevation," Journal of the American Medical Association, vol. 293, no. 4, pp. 427-436, 2005.

[70] "Randomised controlled trial of subcutaneous calcium-heparin in acute myocardial infarction," The Lancet, vol. 2, no. 8656, pp. 182-186, 1989.

[71] "Effectiveness of intravenous thrombolytic treatment in acute myocardial infarction. Gruppo Italiano per lo Studio della Streptochinasi nell'Infarto Miocardico (GISSI)," The Lancet, vol. 1, no. 8478, pp. 397-402, 1986.

[72] J. H. Chesebro, G. Knatterud, R. Roberts et al., “Thrombolysis in myocardial infarction (TIMI) trial, phase I: a comparison between intravenous tissue plasminogen activator and intravenous streptokinase. Clinical findings through hospital discharge," Circulation, vol. 76, no. 1, pp. 142-154, 1987.
[73] F. M. Turazza and G. Cucchi, "Prognostic stratification at discharge after acute myocardial infarct: the significance of the female sex. Participants in the GISSI-2 study. Gruppo Italiano per lo Studio della Streptochinasi nell'Infarto Miocardico," Giornale Italiano di Cardiologia, vol. 24, no. 12, pp. 1585-1595, 1994.

[74] M. L. Simoons, P. W. Serruys, M. vd Brand et al., "Improved survival after early thrombolysis in acute myocardial infarction. A randomised trial by the Interuniversity Cardiology Institute in The Netherlands," The Lancet, vol. 2, no. 8455, pp. 578-582, 1985.

[75] S. Yusuf, J. Wittes, and L. Friedman, "Overview of results of randomized clinical trials in heart disease. II. Unstable angina, heart failure, primary prevention with aspirin, and risk factor modification," Journal of the American Medical Association, vol. 260, no. 15, pp. 2259-2263, 1988.

[76] P. Theroux, H. Ouimet, J. McCans et al., "Aspirin, heparin, or both to treat acute unstable angina," The New England Journal of Medicine, vol. 319, no. 17, pp. 1105-1111, 1988.

[77] J. A. Cairns, M. Gent, and J. Singer, "Aspirin, sulfinpyrazone, or both in unstable angina. results of a Canadian Multicenter Trial," The New England Journal of Medicine, vol. 313, no. 22, pp. 1369-1375, 1985.

[78] H. D. Lewis Jr., J. W. Davis, D. G. Archibald et al., "Protective effects of aspirin against acute myocardial infarction and death in men with unstable angina. results of a veterans administration cooperative study," The New England Journal of Medicine, vol. 309, no. 7, pp. 396-403, 1983.

[79] D. Moher, A. Liberati, J. Tetzlaff, and D. G. Altman, "Preferred reporting items for systematic reviews and meta-analyses: the PRISMA statement," British Medical Journal, vol. 62, no. 10, pp. 1006-1012, 2009.

[80] M. R. Sousa and A. L. Ribeiro, "Systematic review and metaanalysis of diagnostic and prognostic studies: a tutorial," Arquivos Brasileiros de Cardiologia, vol. 92, no. 3, pp. 229-38, 35-45, 2009.

[81] A. M. Glenny, D. G. Altman, F. Song et al., "Indirect comparisons of competing interventions," Health Technology Assessment, vol. 9, no. 26, pp. 1-134, 2005.

[82] T. Jernberg, P. Johanson, C. Held, B. Svennblad, J. Lindbäck, and L. Wallentin, "Association between adoption of evidence-based treatment and survival for patients with ST-elevation myocardial infarction," Journal of the American Medical Association, vol. 305, no. 16, pp. 1677-1684, 2011.

[83] C. P. Cannon, A. Battler, R. G. Brindis et al., "American College of Cardiology key data elements and definitions for measuring the clinical management and outcomes of patients with acute coronary syndromes: a report of the American College of Cardiology Task Force on Clinical Data Standards (Acute Coronary Syndromes Writing Committee)," Journal of the American College of Cardiology, vol. 38, no. 7, pp. 2114-2130, 2001.

[84] S. Valente, C. Lazzeri, M. Chiostri, L. Osmanagaj, C. Giglioli, and G. F. Gensini, "STEMI patients-the more you bleed, the more you die: a comparison between classifications," Clinical Cardiology, vol. 34, no. 2, pp. 90-96, 2011.

[85] S. V. Rao, K. O’Grady, K. S. Pieper et al., "A comparison of the clinical impact of bleeding measured by two different classifications among patients with acute coronary syndromes," 
Journal of the American College of Cardiology, vol. 47, no. 4, pp. 809-816, 2006.

[86] G. W. Stone, M. Bertrand, A. Colombo et al., "Acute Catheterization and Urgent Intervention Triage strategY (ACUITY) trial: study design and rationale," The American Heart Journal, vol. 148, no. 5, pp. 764-775, 2004.

[87] D. L. Bhatt, A. M. Lincoff, C. M. Gibson et al., "Intravenous platelet blockade with cangrelor during PCI," The New England Journal of Medicine, vol. 361, no. 24, pp. 2330-2341, 2009.

[88] S. Amlani, T. Nadarajah, R. Afzal, R. Pal-Sayal, J. W. Eikelboom, and M. K. Natarajan, "Mortality and morbidity following a major bleed in a registry population with acute ST elevation myocardial infarction," Journal of Thrombosis and Thrombolysis, vol. 30, no. 4, pp. 434-440, 2010.

[89] S. Golder, Y. K. Loke, and M. Bland, "Unpublished data can be of value in systematic reviews of adverse effects: methodological overview," Journal of Clinical Epidemiology, vol. 63, no. 10, pp. 1071-1081, 2010.

[90] P. G. Steg, J. López-Sendón, E. Lopez de Sa et al., "External validity of clinical trials in acute myocardial infarction," Archives of Internal Medicine, vol. 167, no. 1, pp. 68-73, 2007. 


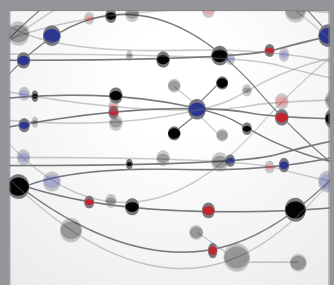

The Scientific World Journal
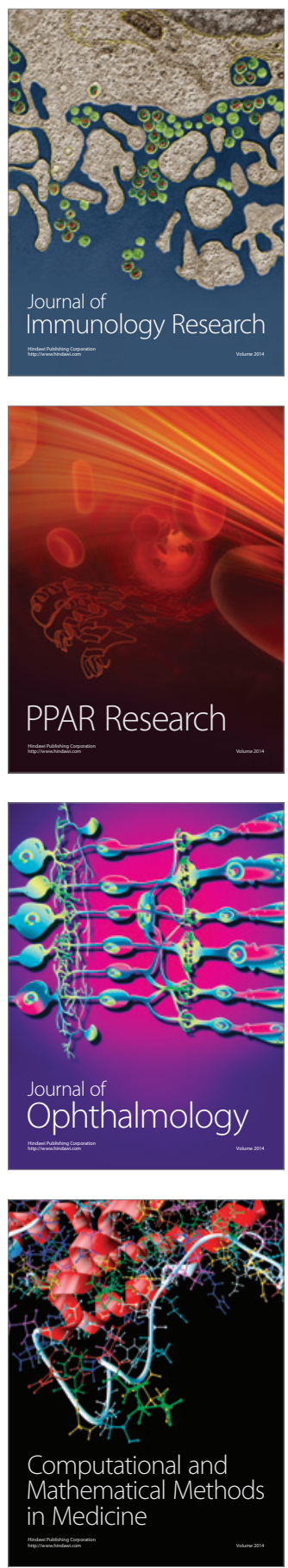

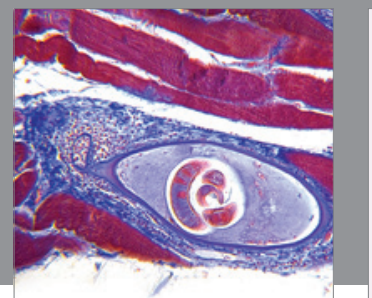

Gastroenterology

Research and Practice
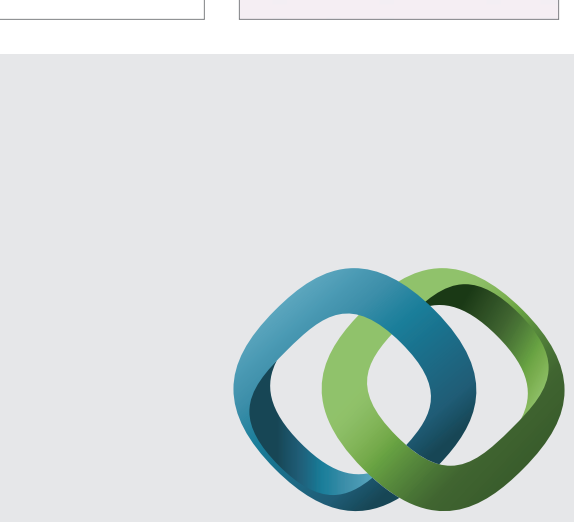

\section{Hindawi}

Submit your manuscripts at

http://www.hindawi.com
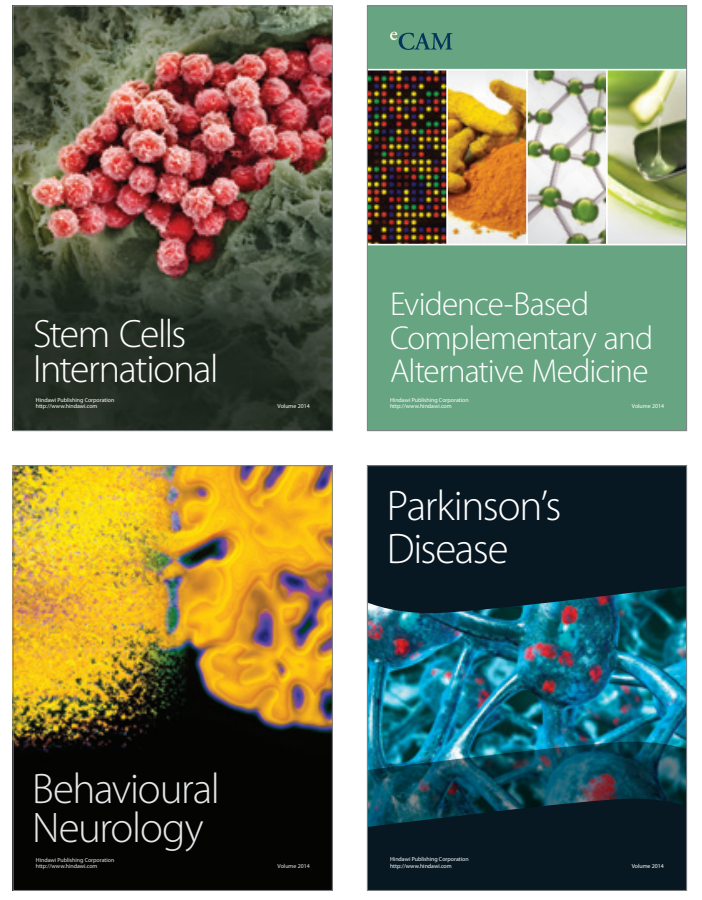
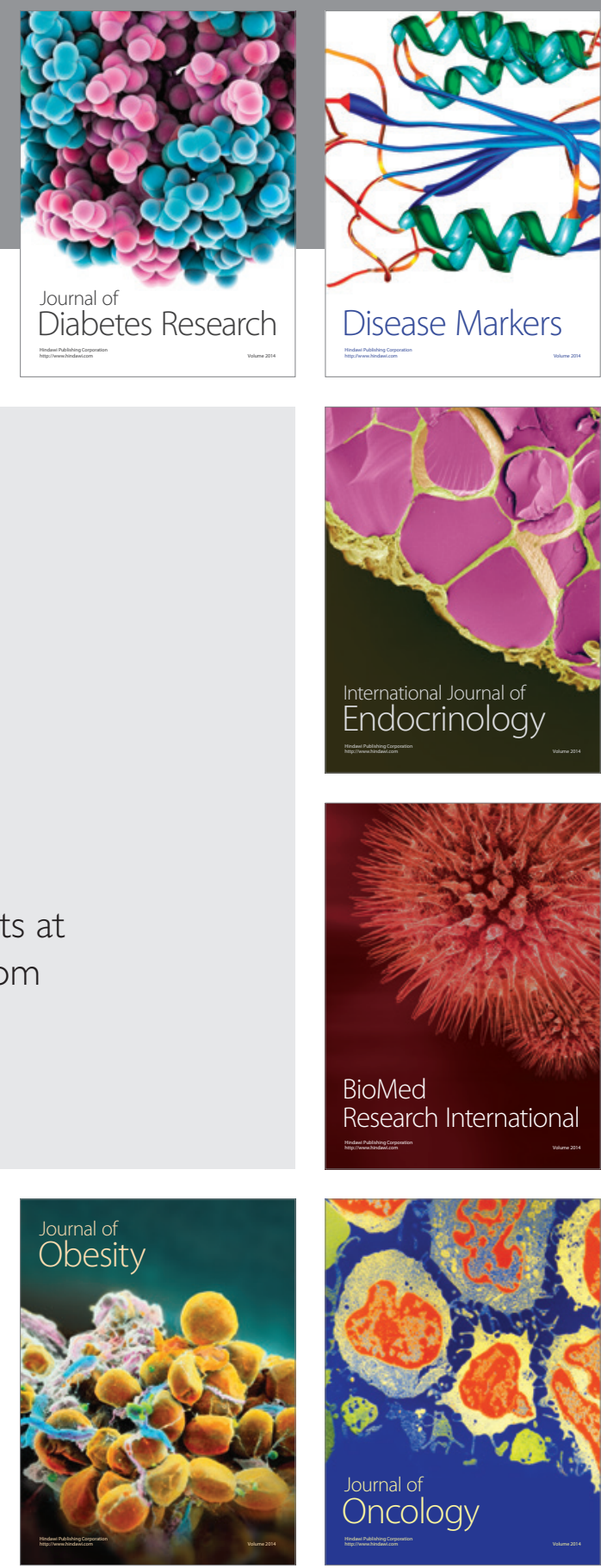

Disease Markers
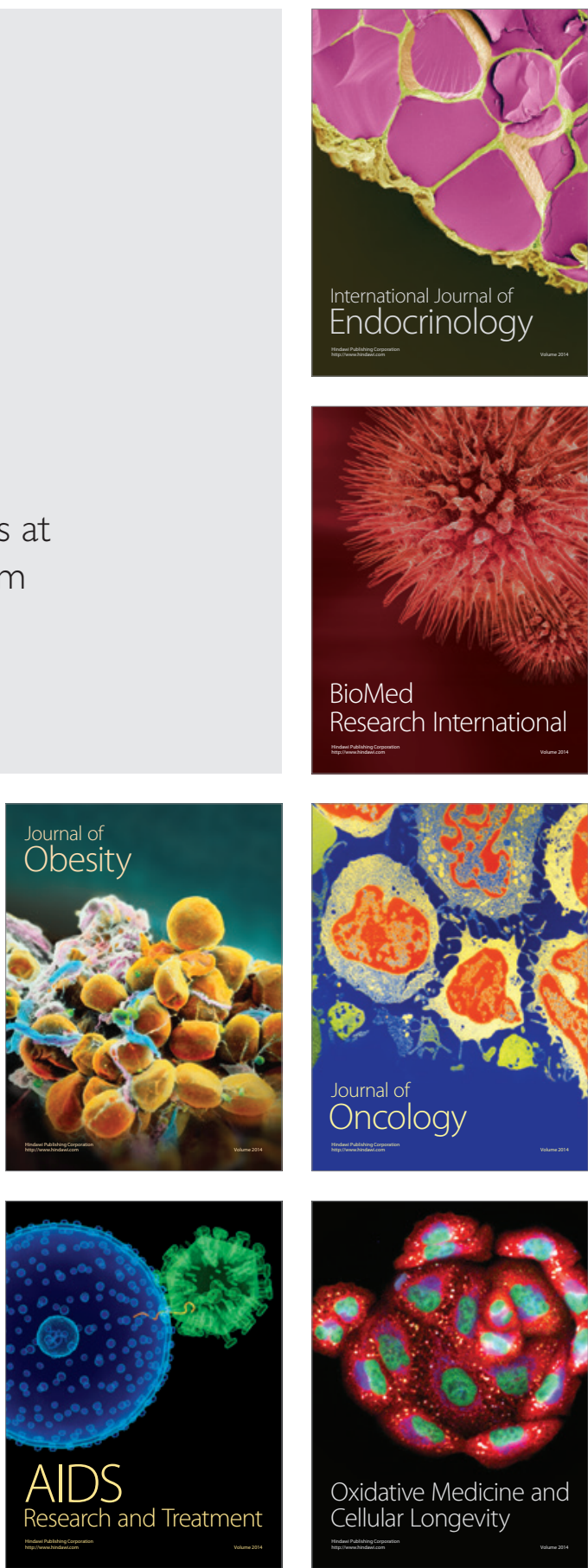